\title{
Assessment of clay soils strengthening under triaxial cyclic loading
}

\author{
Irina Koroleva $^{1 *[0000-0003-4475-988 X]}$ \\ ${ }^{1}$ Kazan State University of Architecture and Engineering, 420043 Kazan, Russia
}

\begin{abstract}
One of the main issues in the design of foundations is the correct forecast of the development of long-term deformations (settlement) of the foundations. Among the main factors affecting settlement, one can single out the neglect of changes in the rheological parameters of the soil in time and the neglect of the loading regime, as well as the processes of soil hardening in time. The work presents the results of a study of the behaviour of samples of clayey soil with a disturbed structure under conditions of triaxial cyclic loading, taking into account the strengthening effect. The relevance of the problem of studying the hardening process is associated with the assessment of the deformability and strength of clays with rheological properties. The tests were carried out in a pneumatic stabilimeter with an artificial soil created of paste. After preparing the samples, they were placed in a sealed container until the start of the test for a period of 1 to 5 days. To establish the ultimate strength of the soil, single static loads were carried out at a given value of the uniform pressure. The main control characteristics during the tests were the maximum and minimum values of the cycle voltages. If the sample did not fail during cyclic loading, it was destroyed by a stepped increase in the static load. The dependences of the change in the strength of a clay soil sample during the holding time before the start of the test were obtained at various values of all-round compression and the amplitude of the cycle. The strength of the soil with a change in the holding time increased up to 1.27 times.
\end{abstract}

Keywords. Clay, cyclic loads, soil testing, triaxial test, strengthening, time-dependent.

\section{Introduction}

It is known that the modern foundations of soil mechanics were formed at the beginning of the last century, in connection with the development of technology, the construction of railways and highways, when the issues of the embankment's operation and subgrade under the influence of dynamic loads became important. The operation of the engineering structure foundations under dynamic loading is determined by the following factors: the properties of the foundation soils, the parameters of the dynamic load and the scheme of its transfer to the structure, material, structure and the nature of the interface between the foundation and the base [1-5]. When a heterogeneous soil medium interacts with the underground part of a

${ }^{*}$ Corresponding author: 79178711218@yandex.ru 
structure of finite rigidity under the influence of static and variable loads, a complex stressstrain state arises, which can lead to additional residual deformations [6-12], as well as emergency situations [13-19]. Creep and relaxation, a decrease in strength under prolonged action of loads are all manifestations of the rheological properties of soils. Without taking into account rheology, the solution of the main problems of soil mechanics is not possible [20-25].

\section{Materials and methods}

Soils are discrete bodies with a complex form of formation and subsequent changes. The multicomponent nature of soils, porosity, complex composition up to the presence of colloids and biota, structural bonds between particles, changes in properties under the influence of various natural and man-made influences distinguish soils from ordinary structural materials.

Cohesive (clay) soils, composed of lamellar-flaky minerals, are more sensitive to static loads, especially if they are sufficiently moistened, but they react little to dynamic influences due to the presence of colloidal crystallization bonds between mineral particles. The values of the total deformation moduli depend on the range of loads in which they are determined [23-26].

To study the nature of the behavior of clay soil under static and cyclic loads, a series of tests of samples of natural and artificial soils were carried out in a triaxial compression device - a stabilometer with the support of the «ASIS» computing system (Fig. 1) in the laboratory of soil science of the department of bases and foundations, dynamics of structures and engineering geology of KGASU was carried out. All parameters of laboratory work were taken according to the current regulatory methodology for the scheme of unconsolidated-undrained tests.

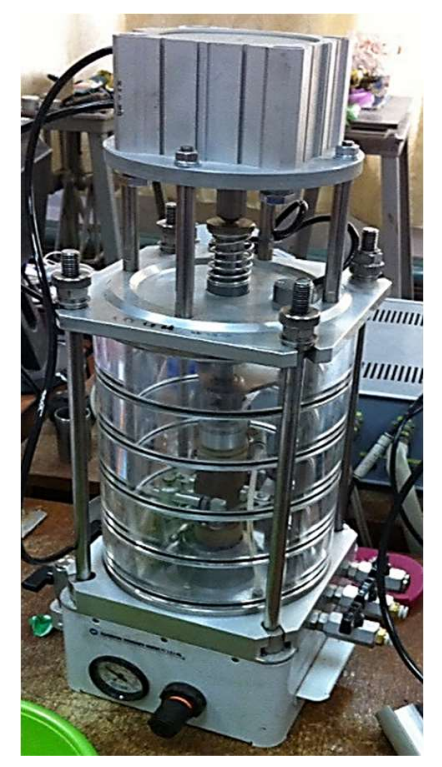

Fig. 1. Triaxial compression device - stabilometer.

The tests were carried out on artificially created compacted soil, made by mixing dry soil and water with a percentage of $23 \%$. The ground mass was hammered into a special shape, from which, after the required time, four standard specimens with dimensions of $76 \mathrm{~mm}$ in height and $38 \mathrm{~mm}$ in diameter were cut out, which were subsequently recorded for static and cyclic loads in a triaxial compression device, a stabilometer. 
The method of static testing is to find the strength characteristics of the soil. For this, the «crushing» scheme was used at a given constant value of the all-round pressure.

The method of cyclic testing is as follows: prepared soil samples are subjected to comprehensive static compression, simulating the natural stress state $\sigma_{l}=\sigma_{2}=\sigma_{3}$. After the stage of deviatorial loading, applied in steps of $10 \%$ until a value equal to the maximum dynamic load $\sigma_{d}$ is reached, the cyclic action is activated. This impact occurs continuously without waiting for the conditional stabilization of relative deformations $N$ times. If the sample withstands all $N$ cycles and does not collapse, the stabilometer brings it to destruction stepwise according to the «crushing» scheme. Thus, the experimental research program included two series of experiments. In the first series, the holding time of the sample before the start of the test was changed and the sample was subjected to cyclic loading as described above (Fig. 2a). In the second series, in addition to exposure before the start of the test, the sample rested after application of 100 cycles from 1 day to 5 days, and then collapsed with a gradually increasing static load (Fig. 2b). In each series, at least three twin specimens are tested with the same loading parameters.

a)

$\sigma 1, \mathrm{kPa}$

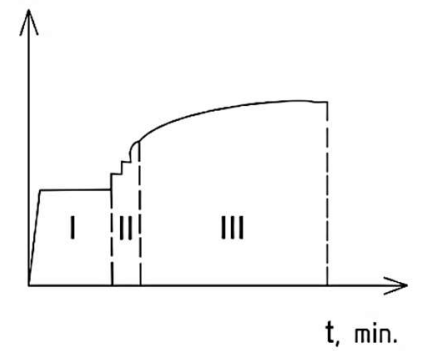

b) $\sigma 1, \mathrm{kPa}$

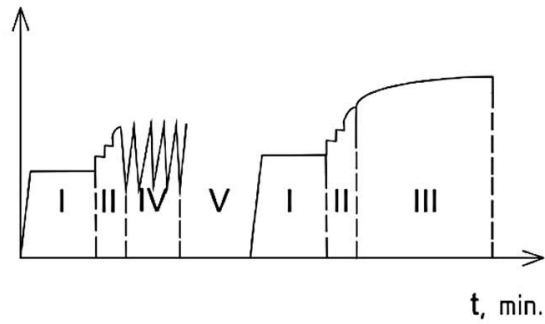

Fig. 2. Loading modes: a) Series 1; b) Series 2. I - all-round compression stage; II - deviatoric loading stage; III - crushing stage; IV - cyclic loading stage; V - rest stage.

During cyclic loading, a clay soil sample, depending on the values of the maximum and minimum cycle stresses, is destroyed at a lower deviator value when compared with static loading. In the case when the destruction of a soil sample during the application of a cyclic load did not occur (this is often observed at low cycle amplitudes), with further destruction by a static load, an increase in the strength of the soil can be observed in comparison with a sample that was not subjected to cyclic loading [26]. In connection with the above, when developing the research program, it was customary to evaluate the change in the vertical deformation of the sample at the stage of cyclic loading and the strength of the soil if the sample withstood a specified number of cycles and was destroyed by a static load. As the main indicators of soil hardening processes, a change in the rate of increase in deformations at the $10^{\text {th }}, 50^{\text {th }}$ and $100^{\text {th }}$ cycles, respectively, as well as an increase in soil strength at the end of the test were taken.

Laboratory studies were carried out on samples of disturbed clays, in which the number of plasticity $I_{p}=17,3$. The rate of restoration of bonds between solid particles in soils with such a content of clay particles is not very high, so it was decided to introduce the factor «time». After preparation, soil samples were kept in a desiccator from 1 day to 5 days. After this «holding», the samples were subjected to triaxial compression with a vertical cyclic deviatorial load.

\section{Results and discussion}

In the first series of experiments (Fig. 3), it was found that in the process of cyclic loading over the interval from 10 to 50 cycles, vertical deformations decreased by $30 \%$ for specimens with «holding» for 5 days, and by $20 \%$ for «holding» for 2 days. At the same time, on the 
$100^{\text {th }}$ cycle, a decrease in the increase in deformations by $60 \%$ and $10 \%$, respectively, was established in comparison with the deformation of the sample with an exposure of «1 day».

Under cyclic loading, an increase in holding time leads to an overall reduction in vertical deformation. A decrease in the deformability of the soil of the disturbed structure indirectly indicates the restoration of structural bonds in the soil of the disturbed structure.

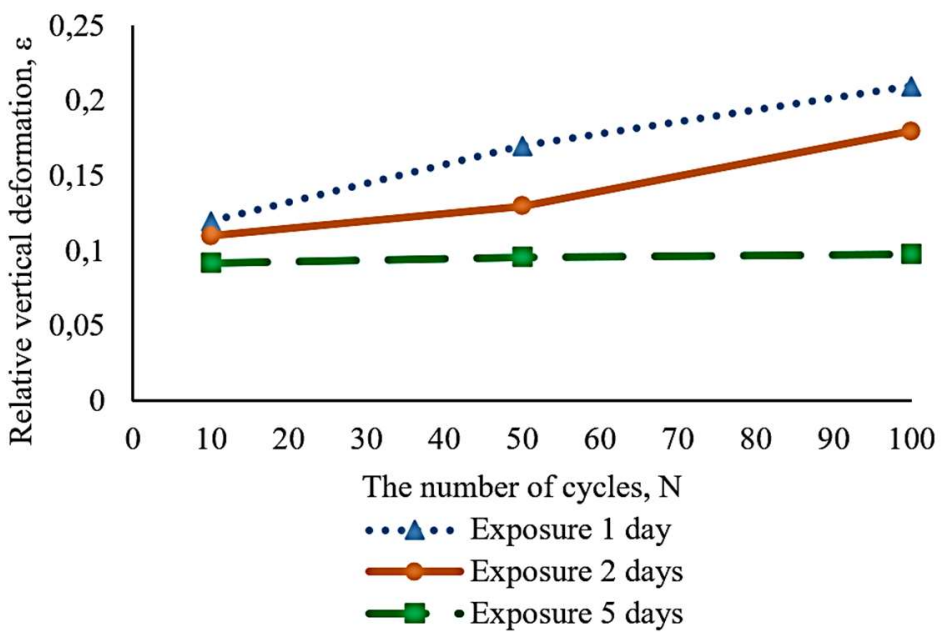

Fig. 3. Changing the soil deformation during cyclic loading as a function of the sample time delay before the test.

The change in the strength of the samples, taking into account the holding time before the start of the test, was considered as the main indicator of the strengthening of the soil of the damaged structure. The strength of the soil is understood as the vertical pressure $\sigma_{l}$, at which the samples were destroyed.

Specimens of the first series after exposure and cyclic loading failed at a higher value of $\sigma_{l}$ than under static loading, so for 1 day the hardening was $13 \%, 2$ days $-24 \%$, and for 5 days - up to $29 \%$ (Fig. 4). It should be noted that the sample tested without «holding» did not withstand 100 cycles and failed in the course of cyclic loading, the value of which was $70 \%$ of the breaking value $\sigma_{l}$ according to the results of static loading.

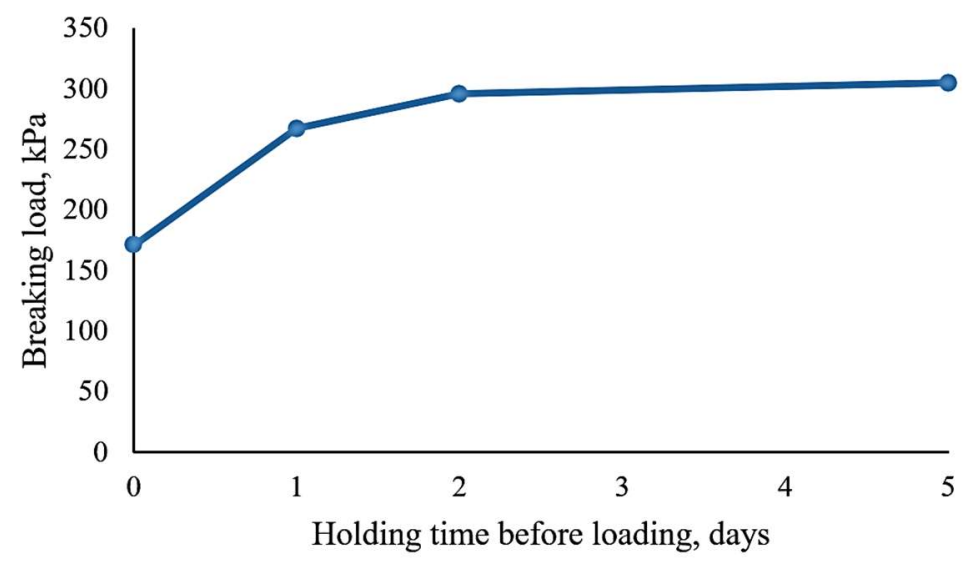

Fig. 4. Dependence of soil strength in the process of cyclic loading on the holding time of the sample before the start of the test. 
A second series of experiments was performed with samples held in a desiccator prior to testing and during the «rest» stage (Fig. 5). In cases where the sample was subjected to allround compression $\sigma_{2}=100 \mathrm{kPa}$, an increase in the total holding time from 1 to 5 days led to an increase in strength on the first day by $4 \%$, on the second day by $14 \%$, and on the fifth day by $17 \%$. In the series, where the horizontal pressure was $\sigma 2=200 \mathrm{kPa}$, the growth of soil strength in the first day was up to $35 \%$, in the next - up to $47 \%$. The foregoing allows us to conclude that the strengthening of clay soil is influenced by both the time between the blocks of the application of the active load and the magnitude of the all-round compression.

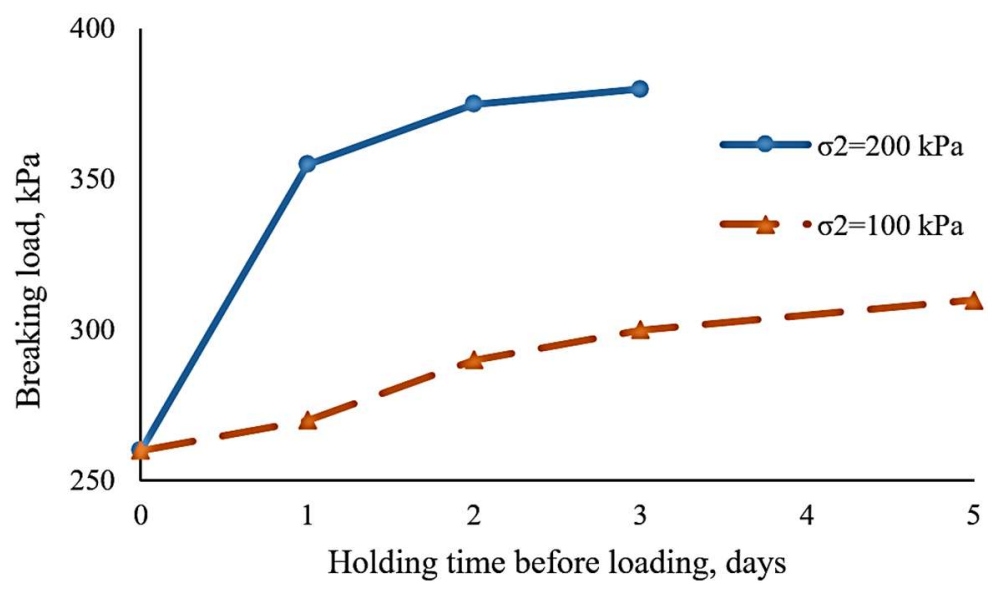

Fig. 5. Dependence of soil strength in the process of cyclic loading on the holding time of the sample before the start of the test and the value of all-round compression.

In general, according to the results of a series of cyclic loading experiments with different values of the magnitude of all-round compression, it was found that the clay soil is hardened up to $27 \%$.

\section{Conclusions}

Experimental studies of changes in deformation and strength parameters of clay soil under cyclic triaxial compression have been carried out. It has been established that the processes of strengthening the soil of the disturbed structure depend on the holding time of the samples after fabrication before the start of loading, as well as on the «rest» time between the loading blocks and the magnitude of all-round compression. Strengthening of the soil is manifested in an increase in the breaking load by $27 \%$ and a decrease in the deformability of the sample. With an increase in the vertical pressure step under cyclic loading, soil hardening occurs faster, and vertical deformation decreases.

\section{References}

1. K. Terzaghi. Erdbaumechanik auf Bodenphysikalischer Grundlage. Deuticke, Vienna, 399 (1925).

2. H.B. Seed. Soli liquefaction and cyclic mobility evaluation for level ground during earthquakes. Journal of ASCE, 105 T2, (1996).

3. K. Ishihara. Soil Behaviour in Earthquake Geotechnics. Saint-Petersburg, 379 (2006).

4. L.R. Stavnitzer. Seismic resistance of bases and foundations. Publishers ASV, Moscow, 448 (2010). 
5. E.A. Voznesensky. The behavior of soils under dynamic loads. Publishers MSU, Moscow, 288 (1997).

6. V.A. Ilyichev, R.A. Mangushev. Directory geotechnics, Bases, foundations and underground structures. M.: ASV, 728 (2014).

7. V.A. Ilyichev et al. Technological Soil Mechanics in Underground. Construction IOP Conf. Ser.: Mater. Sci. Eng. 1079042056 (2021). DOI: 10.1088/1757-899X/1079/4/ 042056.

8. V.P. Petrukhin. Geotechnical problems of construction in Moscow - the largest metropolis of Russia. Proceedings of the international. Conference - Geotechnical problems of megacities, GEOMOS2010, 2010, Moscow, Russia (2010).

9. R. Katzenbach et al. Soil-structure-interaction of Tunnels and Superstructures During Construction and Service Time, J. Procedia Engineering 57, (2013). DOI: 10.1016/j.proeng.2013.04.007.

10. H. Karoui, M. Bouassida. Assessment of observed of behavior of Sidi El Barrak Dam, J. Innovative Infrastructure Solutions 1 (1), (Tunisia) (2016). DOI: 10.1007/s41062-0160044-5.

11. T.-L. Gouw, A. Gunawan. Vibrocompaction proposed design guideline for practicing engineers, Proceedings of the $16^{\text {th }}$ Asian Regional Conference on Soil Mechanics and Geotechnical Engineering, ARC 2019, 2-5 Sept 2019, Taipei, Taiwan (2019). https://www.researchgate.net/publication/339780965_Vibrocompaction_Proposed_Desi gn_Guideline_for_Practicing_Engineers.

12. Ilizar T. Mirsayapov, N.N. Aysin. Influence of a deep construction pit on a technical condition of surrounding buildings, Proceedings of the International Conference on Geotechnics Fundamentals and Applications in Construction: New Materials, Structures, Technologies and Calculations, St.-Petersburg, Russia (2019). DOI: 10.1201/9780429058882-38.

13. D. Lombardi, S. Bhattacharya, M. Hyodo, T. Kaneko. Undrained behaviour of two silica sands and practical im-plications for modelling SSI in liquefiable soils, J. Soil Dyn Earthquake Eng. 66 (2014). DOI: 10.1016/j.soildyn.2014.07.010.

14. S. Bhattacharya et al. Liquefaction of soil in the Tokyo bay area from the 2011 Tohoku (Japan) earthquake, J. Soil Dyn. Earthquake Eng. 31 (11), (2011). DOI: 10.1016/j.soildyn.2011.06.006.

15. K. Goda, G. Campbell, L. Hulme, B. Ismael, L. Ke, R. Marsh, et al. The 2016 Kumamoto earthquakes: cascading geological hazards and compounding risks, Front Built Environ 2 (19), (2016). DOI: 10.17863/CAM.7462.

16. G. Chiaro, T. Kiyota, R.M. Pokhrel, K. Goda, T. Katagiri, K. Sharma. Reconnaissance report on geotechnical and structural damage caused by the 2015 Gorkha Earthquake, Nepal Soils Found. 55 (5), (2015). DOI: 10.1016/j.sandf.2015.09.006.

17. Y. Huang, X. Jiang. Field-observed phenomena of seismic liquefaction and subsidence during the 2008 Wenchuan earthquake in China. Nat Hazards 54 (3), (2010). DOI: 10.1007/s11069-010-9509-6.

18. R.P. Orense, N.A. Hickman, B.T. Hill, M.J. Pender. Spatial evaluation of liquefaction potential in Christchurch following the 2010/2011 Canterbury earthquakes, Int. J. Geotech. Eng. 8 (4), (2014). DOI: 10.1179/1939787913Y.0000000028.

19. Shunji Fujii, Noriaki Isemoto, Yasuhiko Satou, Osamu Kaneko, Hideki Funahara, Toshiaki Arai, Kohji Tokimatsu (Professor). Investigation and Analysis of a Pile Foundation Damaged by Liquefaction during the 1995 Hyogoken-Nambu Earthquake, J. Soils and Foundations 38, (1998). DOI: 10.3208/sandf.38.Special_179.

20.Z.G. Ter-Martirosyan, A.Z. Ter-Martirosyan, Ye.S. Sobolev. Creep and vibrocreep of soils, Proceedings XIV international symposium on the rheology of soils - Future directions of the theory and practice of rheology and soil mechanics. Kazan, (2014). 
21. I.T. Mirsayapov, I.V. Koroleva. Computational Model of the Carrying Capacity of a Reinforced Foundation with Cyclic Loading, J. Soil Mech. Found. Eng. 52, (2015). DOI: 10.1007/s1 1204-015-9328-6.

22. T. Tanaka, Mohri Yoshiyuki, A.Zh. Zhussupbekov. Elasto-plastic and Viscoplastic Finite Element Analysis - Direct Shear Box Test and Dynamic Deformation of Reinforced Embankment Dam, Proceedings XIII international symposium on the rheology of soils Achievements, Problems and Perspective Directions of Development for the Theory and Practice of Soil Mechanics and Foundation Engineering Problems. Kazan, (2012).

23.Z.G. Ter-Martirosyan, A.Yu. Mirnyj, Ye.S. Sobolev. Features of determining the parameters of modern soil models during laboratory tests, J. Geotechnika 1, (2016).

24. I.T. Mirsayapov, I.V. Koroleva. Bearing capacity and deformation of the base of deep foundations' ground bases, Proc. intern. symp., Seoul, Korea - Geotechnical Aspects of Underground Construction in Soft Ground / Balkema, Lieden (2014).

25. I.T. Mirsayapov, I.V. Koroleva. Strength and deformability of clay soil under different triaxial load regimes that consider crack formation, J. Soil Mechanics and Foundation Engineering 53, 1 (2016). DOI: 10.1007/s11204-016-9356-x.

26. I.T. Mirsayapov, I.V. Koroleva. Feature's deformation of clayey soils under cyclic triaxial compression, International Journal of Geotechnical 6, (2010). 